\title{
A GEOGRAFIA QUE SE PRETENDE E A GEOGRAFIA QUE SE ENSINA: OS DESAFIOS DO PIBID NA PRÁTICA DO ENSINO DE GEOGRAFIA NAS ESCOLAS PÚBLICAS BRASILEIRAS
}

\author{
The geography that is intended and geography that teaches: the challenges of PIBID in the \\ practice of geography education in the brazilian public schools \\ Debora Cristina Vieira de Simas* \\ * Mestranda do PPG em Geografia da UERJ- FFP. Professora da Rede Estadual do RJ- deborasimas.uff@gmail.com.
}

Recebido em 06/08/2018. Aceito para publicação em 20/08/2018.

Versão online publicada em 03/09/2018 (http://seer.ufrgs.br/paraonde)

\begin{abstract}
Resumo:
O objetivo deste artigo é analisar as práticas curriculares desenvolvidas no PIBID no subprojeto de Geografia, "Saber Escolar e Formação Docente na Educação Básica" da UERJ- FFP, financiado pela CAPES-MEC. Este programa visa à formação do professor, o apoio à escola pública na transformação do espaço escolar e o aprimoramento no ensino de Geografia. No atual cenário de contradição e grande desigualdade social, o PIBID vem se colocando como resistência. A partir da metodologia do materialismo histórico dialético que permite entrecruzar as contradições e conflitos vividos na escola no atual contexto histórico com as contradições da própria Geografia que se ensina, exercitando o "raciocínio geográfico", para assim atuar de maneira eficaz no espaço, articulando o espaço "vivido ao percebido e ao produzido" à prática social.
\end{abstract}

Palavras-chave: Ensino de Geografia; PIBID; Formação Docente.

\begin{abstract}
:
The objective of this article is to analyze the curricular practices developed at "PIBID" on the Geography subproject "Saber Escolar e Formação Docente na Educação Básica" - "School Knowledge and Faculty Schooling for Primary School" of UERJ- FFP, sponsored by CAPES-MEC. The aforementioned program aims at Faculty Schooling, supporting public schools on the transformation of the school environment and the enhancement of Geography Teaching. In the current contradictory setting and overwhelming social inequality, "PIBID" stands as resistance. Applying historical dialectic materialism which allows comparison between the discrepancies and conflicts experienced at school in the current historical context and taught Geography's own contradictions, exercising "geographical thinking", it is possible to act effectively in the school space, articulating the space "lived to perceived to produced" to social practice.
\end{abstract}

Key-words: Geography Teaching; PIBID; Teachers' education.

\section{Introdução}

A discussão entre as diferentes práticas curriculares traz a luz o debate das questões relativas à função e ao papel da escola na contemporaneidade e da disciplina da Geografia no espaço escolar. Nesse contexto, o presente artigo busca reunir alguns pontos de reflexão relativos ao papel do conhecimento disciplinar nas práticas curriculares da Geografia na Escola Básica onde atua o PIBID com o subprojeto de Geografia "Saber Escolar e Formação Docente na Educação Básica" da UERJ-FFP, bem como sua relação com os conhecimentos 
emergentes do mundo vivido pelos alunos. Neste sentido, problematiza alguns dos muitos desafios enfrentados nas escolas públicas brasileiras, fundamental à compreensão da função social da Geografia.

Apoia-se no referencial oferecido pela tríade de Henri Lefebvre (2000) do espaço "vivido, concebido e percebido", no "raciocínio geográfico" e na "espacialidade diferencial" de Yves Lacoste (1988) e na recente definição da Geografia como "ciência das práticas e dos saberes espacial" de Ruy Moreira (2013). A metodologia do materialismo histórico dialético permite entrecruzar as contradições e conflitos vividos na escola no atual contexto histórico com as contradições da própria Geografia que se ensina. A prática deste subprojeto propõe formas de trabalho diferenciadas, na perspectiva da educação emancipatória, balizado pela ponte Universidade-Escola-Comunidade, partindo do cotidiano dos alunos, visando à articulação prática-teoria-prática dentro na escola.

A partir da metodologia estabelecida, o presente artigo inicia apresentando os problemas da escola e da Geografia que se ensina. Em seguida as abordagens teóricas que permitem pensar as questões levantadas e, por fim, práticas curriculares que buscam superar esses desafios.

\section{Os problemas da escola e da Geografia que se ensina}

A precariedade das escolas públicas não é novidade: o desinteresse dos alunos nas atividades escolares, a ausência dos familiares, a dificuldade de leitura e escrita, falta de estrutura e materiais básicos. Existem ainda as dificuldades enfrentadas nas próprias condições de trabalho pelas diversas categorias de trabalhadores nas instituições de ensino pública: atraso de salários em algumas redes (que já são defasados), a não garantia do planejamento das aulas para todas as matrículas, garantido por lei, porém não cumprido em todas as redes, o excesso de estudantes nas salas de aula e a falta de apoio pedagógico. Destaca-se também a intensificação de políticas meritocráticas com critérios quantitativos - e não qualitativos - para alcance das metas e otimização de custos, dificultando o trabalho de todos os membros da comunidade escolar dentre os quais, os professores.

Esta precária condição de existência das escolas públicas brasileiras, em maior ou menor proporção dependendo do estado e/ou município onde se localizam, apresentam o cenário da profunda desigualdade social vivida pela população brasileira na atual fase de desenvolvimento capitalista .

Somado as contradições espaciais, existem os problemas vividos pelo ensino de Geografia na Escola Básica. A Geografia "desinteressada", supostamente neutra em relação aos problemas espaciais vividos cotidianamente pelos estudantes e população como um todo, não explicita os vínculos entre a prática espacial dos diferentes sujeitos da produção do espaço e o conhecimento escolar. Mesmo mais explicativa, ainda utiliza o método descritivofragmentário que separa a abordagem da sociedade da dinâmica da natureza.

É possível nesta escola um processo pedagógico que parta do espaço vivido pelos alunos e suas práticas cotidianas, e que reverta o ensino meramente descritivo e reprodutivista? É o que será exposto, a partir da idéia de que a Geografia possa ser uma ciência articulada com as práticas e saberes espaciais. 


\title{
3. A escola que queremos
}

Para que seja um lugar de reflexão e construção de cidadania, é preciso pensar a escola numa perspectiva que abarque e valorize os conhecimentos e experiências dos diversos grupos sociais que a compõem. Desta forma, apontam Castellar e Stefenon $(2015$, p.16) que a educação transmite uma parte selecionada da cultura, ou seja, a face institucionalizada da mesma. A sua parte reificada e tornada currículo. Assim, há que se questionar a serviço de qual cultura está à Geografia que se ensina e que está institucionalizada na escola.

No texto "Para que servem as escolas", Michael Young (2007), expressa as tensões e conflitos de interesses na sociedade. 0 texto aborda a expansão da escolarização e a destaca a importância da escola em oportunizar aos alunos a aquisição do conhecimento escolar como um "conhecimento poderoso".

Baseando- se na análise de Basil Bernstein, Young (2007) sugere que o currículo deve ser mais acessível e relevante para propiciar as condições favoráveis de aprendizado. Principalmente para os alunos que já são desfavorecidos pelas suas condições sociais, condições estas cotidianas das escolas públicas brasileiras.

Essa noção de que "a classe social permanece como maior regulador na distribuição dos estudantes no que diz respeito ao sucesso e fracasso escolar" são percebidas em Lucíola Santos (2003, p. 23, 24), pois a escola, metaforicamente, "é como um espelho que reflete imagens positivas e negativas... imagens que são a projeção da hierarquia de valores, de valores de classe".

Santana Filho (2006) nos chama atenção para um importante fato a respeito da escola:

\begin{abstract}
Num breve balanço das transformações ocorridas no mundo da cultura ocidental no último século, encontramos inúmeras justificativas para apontar a anacronia da escola, destacar seus limites e fracassos em promover a ciência e qualificar mão-de-obra para essa era do conhecimento - especialmente em países como o nosso. (...) esta mesma escola ainda permanece como possibilidade de esperança para milhões de brasileiros e de outros povos. Basta testemunhar como em suas representações estão presentes a ideia de realização e conquista, de caminho para melhoria de qualidade de vida e trabalho, em suma, de ascensão social. (...) nós, que nela vivemos, carregamos uma responsabilidade intransferível da qual não devemos abdicar - o ensino escolar público deve fazer a diferença para grande parcela da população brasileira. (SANTANA FILHO, 2006, s/p)
\end{abstract}

A escola é um espaço contraditório e conflituoso. É a mesma responsável pela melhoria de vida e ascensão social de significativa parcela da população brasileira. Sendo assim, mesmo precarizada, é um espaço importante de atuação.

Castellar e Stefenon (2015, p.17) chamam a atenção para a "relação da escola com o contexto amplo das estruturas sociais, as quais refletem- se mutuamente entre si". E que, portanto, deveria se comprometer em garantir três níveis de direitos básicos: (1) no nível pessoal, garantir a formação dos indivíduos; (2) no nível social permitir a inclusão das pessoas sem que sejam absorvidas pelo conjunto da sociedade; e (3) no nível político, garantir o direito à participação nos contextos amplos de decisão.

A escola e professores exercem o papel imprescindível na sociedade. Conforme aponta Santana Filho (2006, s/p) "prioritariamente, ouvir e atender com responsabilidade àquilo que tantas famílias aspiram com contribuição nossa para o hoje e o futuro para seus jovens, suas 
crianças - e por que não, seus adultos".

Partindo dessas premissas, as escolhas conceituais e metodológicas tem que fazer sentido e ir de encontro a uma proposta de escola, que permita elencar parâmetros para pensar este espaço, o quê e como ensinar. É fundamental ter clareza de que conhecimento se quer trabalhar. Isso leva, enquanto professores-geógrafos, a pensar o lugar da Geografia na escola e que caminhos tomar no processo de construção de conceitos geográficos.

Ao pensar e fazer uma Geografia é preciso saber o que se pretende com esta ciência. Considerar as contradições do espaço, na integração da Geografia a partir dos seus autores seminais, nos proporciona o ensino alerta as contradições espaciais. Conceber que o espaço serve a uma produção social nos faz pensar uma Geografia que sirva a construção cidadã e que o faça saber pensar o espaço. Desta forma, assumir uma maneira diferente de se perguntar sobre o mundo.

\section{A Geografia que se pretende}

Em 1988 Lacoste já havia questionado sobre o caráter enfadonho e descritivo da disciplina de Geografia meramente expositiva que não proporcionava grande serventia aos alunos além de decorar informações generalistas e que não apresentavam relação explicita com a prática social dos estudantes.

Neste sentido, Moreira (1987) faz uma releitura do passado, elucidando que a Geografia vem servindo ao poder dominante, mas pode e deve ser virada ao avesso, e fazer uso dela para movimentar e combater. A interação entre universidade e escola permite fortalecer práticas curriculares de Geografia, evidenciando o importante o papel exercido pela ponte entre as instituições de ensino para a difusão do conhecimento para a sociedade como um todo.

Moreira (1987, p. 103, 104) chama atenção para que não se escondam, com novas palavras, concepções e práticas velhas, ou seja, a utilização de veículos e aparelhos altamente tecnológicos para demonstrar ilustrações e números que continuam desconectados com as práticas sociais dos alunos. Para que de fato haja uma Geografia que, em sua gênese seja concebida para questionar e pensar as práticas sociais vigentes, se faz indispensável à articulação bem estruturada entre "a forma ("a Geografia do Brasil que se ensina") e o conteúdo ("o Brasil da Geografia que se ensina") .

É um compromisso, indissociável a nossa prática, pensar o que se pretende com o conteúdo ensinado e a forma de mediar esta aquisição de conhecimento para os alunos nas mais diversas esferas e níveis de conhecimento. Não basta o professor ter o domínio do conteúdo que trabalha; é fundamental que domine os fundamentos de sua disciplina e saiba se posicionar sobre o papel da Geografia. A proposta de trabalho deve contribuir para o desenvolvimento da aprendizagem e da autonomia de seus alunos. 0 ensino de Geografia deve ser um saber que parte do seu cotidiano, das práticas sociais, conectado a vida social, expandindo a capacidade analítica do aluno, a partir do seu espaço vivido.

Lacoste (1988, p.11) ressalta que é, sobretudo quando o discurso geográfico parece inútil que este exerce a função mistificadora mais eficaz e que nós veremos que as consequências da mistificação da Geografia são graves. Desmistificar é explicitar o seu objetivo político e a sua vinculação com as práticas sociais. Assim a Geografia, a ser ensinada, deve estimular a 
reflexão crítica e se propor a ser uma importante ferramenta na formação de professores e uma prioridade àqueles que procuram compreender com mais profundidade a situação do ensino de Geografia no Brasil. A concretização desse ideal requer o compromisso político do educador.

Compreender os currículos postos e o que se pretende com eles, se faz a primeira das muitas prioridades no ensino da disciplina de Geografia. Castellar e Stefenon apresentam a importância de assumir determinadas escolhas:

Assumir que os alunos precisam compreender as categorias, conceitos e conteúdos geográficos, cientificamente, pressupõe entender o significado de um currículo escolar bem estruturado do ponto de vista conceitual e a sua articulação com o campo pedagógico. Os conceitos, por sua vez, devem estar integrados aos conteúdos e as situações do cotidiano, fundamentados epistemologicamente por meio das categorias e dos princípios geográficos. Neste sentido, o aluno, pela mediação do professor, construirá conhecimento e entenderá o conceito no processo de ensino e de aprendizagem, operando no pensamento o significado de uma palavra por meio de outras. (CASTELLAR e STEFENON, 2015, p. 20)

A proposta de articular o campo pedagógico a partir do trabalho do professor com as categorias e conceitos da Geografia, permite transpor o que já está velho, ultrapassado e a não serve para entender o espaço vivido. Pensar a Geografia em seu movimento, interação e complexidade. É deixar de lado o ensino simplista de mera a apreensão fixa de lugares, descrições e estatísticas.

0 ensino de Geografia está além de apresentar uma gama de conteúdos descontextualizados. É entender as conexões entre forma e conteúdo que permita ao aluno compreender o lugar onde vive e assim estabelecer nexos entre outras áreas de vida ou do conhecimento, exercitando seu "raciocínio geográfico" no contexto das práticas espaciais multiescalares da "espacialidade diferencial", conforme propõe Lacoste. Desta maneira, considera-se essencial "a familiarização de cada um com um instrumento conceitual que permite articular, em função de diversas práticas, as múltiplas representações espaciais que é conveniente distinguir, quaisquer que sejam sua configuração e sua escala" (Lacoste, 1988, p. 24). 0 "raciocínio geográfico" pode ser descrito como uma habilidade de suma importância para os objetivos do ensino de Geografia, trata do que Lacoste (1988) chama de "saber pensar espacialmente". Já a "espacialidade diferencial" trata das práticas sociais multiescalares, exigentes da distinção e articulação de suas escalas. Um fenômeno pode ser analisado de acordo com distintas escalas e, para cada uma, apresentar significados diferentes; ou seja, uma mesma questão exige diferentes intervenções que podem variar de acordo com o nível da escala trabalhada. Para Lacoste (1988) este é o caminho para o conhecimento e reconhecimento da cidadania. As multiescalas servem para pensar o espaço nas diversas dimensões possíveis para assim melhor pensar as ações dos sujeitos no/do espaço e assim nele se organizar, visto que passam a reconhecê-lo, e nele lutar e intervir.

Relacionar as ações multiescalares da especialidade diferencial com a realidade vivida pelos alunos vai de encontro ao pensamento Lefebvre (2000), que concebe o espaço e o tempo como sendo socialmente produzidos. Para o autor, o conceito de espaço tem um caráter processual: Ele se dialetiza podendo ser produto-produtor, suporte de relações econômicas e sociais, sendo assim modo de produção da essência, ou seja, modo de produção da vida. As dimensões do "vivido, concebido e percebido" ganham corpo e se materializam no espaço sendo este socialmente produzido. 
É da necessidade de estabelecer práticas para estabelecer seus meios de existência e possibilidades de vida que o homem aos poucos estabelece sua relação com o espaço. A relação homem- natureza parte dessas práticas espaciais. A continuidade dessas práticas, tentativas, erros, acertos, levam a experiências das quais existe um aprendizado. Deste aprendizado através da experiência vêm as escolhas. 0 homem em sua relação com a natureza vai transformando suas práticas em saberes à medida que passa a selecionar sua estratégia de existência. Quanto mais saberes são acumulados, mais aprimoradas são suas práticas espaciais.

Essa relação dialética entre práticas e saberes vai tomando corpo, ampliando-se, transborda a existência do homem indivíduo e passam a fazer parte da vida da comunidade. As práticas e saberes vão se tornando mais complexos, mais aprimorados e no campo das ideias nasce a ciência geográfica. Ciência esta que não está pronta e acabada com velhos rótulos e conceitos fechados, mas que é construída a partir de enunciados pensados nas necessidades e demandas de uma comunidade na dimensão do cotidiano.

Neste sentido a transformação das práticas em saberes e posteriormente em ciência parte de referenciais consistentes para a sua compreensão do mundo. Conforme Couto (2015b, p.8) "Isto significa viver, ver, perceber e pensar o espaço de modo integrado". Neste trajeto onde o sujeito sai de um nível de menor conhecimento para um nível de maior conhecimento o ensino de Geografia traz outra lógica para pensar o espaço, próxima ao cotidiano.

Tal práxis faz parte da proposta do subprojeto de Geografia proposto pela Universidade do Estado do Rio de Janeiro- Faculdade de Formação de Professores (UERJ-FFP), em articulação com as escolas de Educação Básica.

\section{O PIBID e a formação do professor}

O Programa Institucional de Bolsa de Iniciação à Docência (PIBID) apresenta-se como iniciativa para o aperfeiçoamento e a valorização da formação de professores para a Educação Básica, fomentado pela Comissão de Aperfeiçoamento de Pessoal do Nível Superior (CAPES) e viabilizado através de convênio das Instituições de Ensino Superior (IES) em parceria com escolas de Educação Básica. 0 programa tem como objetivos principais: Incentivar a formação de docentes em nível superior para a educação básica; elevar a qualidade da formação inicial de professores; inserir os licenciandos no cotidiano de escolas; mobilizar seus professores como protagonistas nos processos de formação inicial para o magistério; contribuir para a articulação entre teoria e prática necessárias à formação dos docentes. São 313 projetos participantes no PIBID, espalhados por todas as regiões do país ${ }^{1}$. Para uma IES interessada em participar do PIBID é necessário apresentar a CAPES seus projetos de iniciação à docência conforme os editais de seleção publicados. 0 processo seletivo para os bolsistas se dá por meio de seleções promovidas por cada IES, deste modo, podendo integrar o programa com uma das cinco modalidades de bolsa aos participantes do projeto institucional, entre elas a Iniciação à docência. São distribuídas por todo país um total de 90.254 mil bolsas em todo o país ${ }^{2}$.

No Estado do Rio de Janeiro, a UERJ-FFP da qual a presente pesquisadora participa do PIBID, tem como foco principal as escolas públicas no leste da baía de Guanabara (São

\footnotetext{
${ }_{1}^{1}$ Projetos participantes do PIBID. Dados presentes em: http://www.CAPES.gov.br/educacao-basica/CAPESPIBID/relatorios-e-dados.

${ }^{2}$ Bolsas concedidas pelo PIBID no ano de 2014. Dados presentes em: http://www.CAPES.gov.br/educacao-basica/CAPESPIBID/relatorios-e-dados
} 
Gonçalo, Itaboraí, Niterói, etc), periferia da metrópole do Rio de Janeiro, região em que os indicadores sócio-econômico-educacionais expressam baixos níveis de qualidade dos serviços públicos e consequentemente, da qualidade de vida. Em busca de tal melhoria, se faz necessário o acompanhamento dos professores, o estudo continuado e a discussão com a comunidade, bem como, com todos os profissionais envolvidos.

\section{O PIBID da UERJ-FFP e o subprojeto de Geografia}

A emergência do diálogo entre universidade, escola e comunidade escolar para uma melhoria da sociedade pelo caminho da educação básica é um dos objetivos do subprojeto de Geografia do PIBID da UERJ- FFP. Proporcionado pela CAPES o programa é viabilizado através do convênio com a UERJ-FFP com escolas básicas, como o Instituto de Educação Clélia Nanci (IECN), pertencente à rede estadual de ensino e do Colégio Municipal Paulo Reclus Neves Freire, pertencente à rede municipal de São Gonçalo. Tal proposta busca o aprimoramento dos processos de ensino-aprendizagem construindo o conhecimento com qualidade de maneira crítica e dialógica. Neste cenário de contradição e grande desigualdade social das escolas públicas brasileiras, o subprojeto de Geografia vem se colocando como resistência, e propondo formas de trabalho diferenciadas, em busca de uma educação emancipatória visando à ponte Universidade- Escola- Comunidade.

Trazendo os licenciandos em formação para a escola o PIBID contribui para com a IES propiciando aos estudantes de ensino superior a vivência no espaço escolar no cotidiano. Além disso, os alunos da educação básica vivenciam com maior apoio suas experiências pedagógicas na sala de aula ou fora dela, visto que estes licenciandos acompanham a rotina escolar com o professor regente em troca contínua de proposições. Esta troca proporciona experiências diferenciadas aos sujeitos envolvidos na escola: desde o debate dialógico e dialético nas diferentes escalas que envolvem a construção do conhecimento passando pelo pensar a concepção teórico-metodológica do ensino de Geografia e a interação na escola onde os diversos sujeitos interagem na construção do conhecimento de maneira ativa e participativa. Nesta concepção o professor é o mediador da relação entre os estudantes e o conhecimento acumulado e de acordo com a proposta do Subprojeto de Geografia, transformando as práticas em saberes espaciais e saberes em raciocínio geográfico-espacial, conforme defendido anteriormente.

Neste contexto, propõe-se que os alunos sejam preparados para pensar criticamente o que é debatido ao longo das aulas de Geografia para que tal qual a tríade Lefebvreana, (o vivido, percebido e concebido) faça sentido para além da escola. Isso significa dizer que este subprojeto propõe pensar a formação de professores para assim elevar qualitativamente sua intervenção em sala de aula por meio da mediação e por meio desta, as práticas curriculares.

Entre as práticas envolvidas estão reunião de planejamento para a concepção do plano de atividades, levantamento de possibilidades de temas centrais e norteadores do projeto, levantamento bibliográfico para a explanação e debate dos temas, organização de oficinas na escola e na universidade com professores convidados para a formação dos professores supervisores e oficinas direcionadas aos alunos, a construção da Mostra de Trabalhos como culminância do projeto, onde os alunos apresentam seu aprendizado para uma plateia mista de alunos, professores de educação básica e da universidade. Ao fim do ano letivo é construído um relatório onde estão todas as atividades vivenciadas pelos sujeitos envolvidos.

ParaOnde!?, Porto Alegre, v.10, n.1, p.90-98, 2018. Edição Especial: XII ENANPEGE http://seer.ufrgs.br/paraonde Página 96 
O tema de uma das Mostras de Trabalhos do PIBID, o Rio Imboaçu foi trabalhado em diversos vieses, inclusive tema do trabalho final de pós- Graduação da presente pesquisadora . Ao longo da investigação ficou evidente que pesquisar a partir do espaço vivido tornava a busca pelo conhecimento mais interessante. Quando os alunos foram a campo, entrevistaram os moradores e coletaram dados em geral, surgiram as questões a partir de problemas. Desde o início do trabalho, havia uma dificuldade em diferenciar rio e valão, entender os processos e categorias de formação e o que conceitualmente cada um deles significava. A contribuição da Geografia está em auxiliar aos alunos na superação das dificuldades concernentes ao tema, a partir de uma articulação entres os conceitos e a prática do mediados pelo professor. Portanto neste trabalho propõe- se que tanto discente como docente são produtores de conhecimento, apontando assim uma renovação na prática pedagógica partindo das práticas espaciais.

Esta abordagem tem se mostrado de suma importância para a formação inicial e continuada dos docentes incentivando a ponte Universidade-Escola- Comunidade, assim como promovendo a busca pela ciência e a produção do conhecimento pelos alunos. A realização de atividades de campo, a confecção de vídeos, dentre outras atividades, como o tratamento de dados é significativo para o aprimoramento das práticas escolares e problematização das dificuldades enfrentadas na escola básica. Motivados pela interação direta com o espaço vivido e participação da população nesse processo, os alunos para os quais as atividades do PIBID são realizadas apresentam maior interesse, facilitando o processo de Ensinoaprendizagem. As turmas elaboraram banners e jogos interativos para exposição na área de convivência da UERJ-FFP para apresentar o resultado de suas pesquisas.

\section{Considerações Finais}

Para os sujeitos envolvidos no subprojeto de Geografia do PIBID-UERJ-FFP, o ensino de Geografia faz sentido quando o professor de Geografia utiliza-se de uma práxis vinculada às práticas espaciais, relacionando à forma e ao conteúdo para passar a um saber espacial e a um conhecimento científico, partindo de nexos com a realidade vivida pelos sujeitos envolvidos.

Dentro deste cenário, é fundamental a definição dos conteúdos da forma proposta ao ensino de Geografia na escola básica como uma resistência as desigualdades postas no mundo atual. 0 ensino de Geografia poderá proporcionar uma escola que de fato cumpra a sua função social de acordo com a perspectiva aqui adotada: a de emancipadora na construção da cidadania. Pode ser por isso que atualmente o ensino de Geografia na escola básica mais uma vez é questionado. Afinal, "A Geografia - Isso Serve, Em Primeiro Lugar, Para Fazer a Guerra" como já nos alertava Yves Lacoste.

\section{Referências}

CASTELLAR, S. M. V.; STEFENON, D. L. A Ciência Geográfica na escola: pressupostos de um currículo escolar fundamentado no conhecimento escolar. Uni-pluri (Medellin), v. 43, 2015, http://aprendeenlinea.udea.edu.co/revistas/index.php/unip/article/view/23631

COUTO, M. A. C. (2015). Práticas educativas na geografia que se ensina na escola pública brasileira. In: Fernandez Caso, V y R. Gurevich (Dir.). (Org.). Didáctica de la geografía. Prácticas escolares y formación de profesores. 1ed.Ciudad Autónoma deBuenos Aires: 
INDEGEO/REDLADGEO/Ed. Biblos, 2014, v. 1, pp. 251-269.

COUTO, M. A. C. (2015b). A geografia como ciência das práticas e dos saberes espaciais - por um novo modelo clássico de organização curricular. Texto digitado.

LACOSTE, Y. (2010). A Geografia - Isso Serve, Em Primeiro Lugar, Para Fazer a Guerra. Papirus Ed.: S.Paulo-SP.

LEFEBVRE, H. (2000). La production de l'espace. Paris: Éditions Anthropos; 4⿳a a ed.

MOREIRA, R. (1987). O Discurso do Avesso - para a crítica da geografia que se ensina. São Paulo: Dois Pontos.

MOREIRA, R. (2013). Uma ciência das práticas e saberes espaciais. Texto digitado.

SANTANA FILHO, M.M. A educação geográfica na escola: elementos para exercício desafiante da cidadania. Revista Tamoios, São Gonçalo RJ, 2006.

SANTOS, L.C.P.(2003). Bernstein e o campo educacional: relevâncias, influências e incompreensões. Cadernos de Pesquisa, 120, p. 15-49.

YOUNG, M. Para que serve as escolas? Educ. Soc., Campinas, vol. 28, n. 101, set./dez. 2007, p. 1287-1302. http://www.scielo.br/pdf/es/v28n101/a0228101.pdf 